\title{
The Modulatory Action of Vitamin D on the Renin-Angiotensin System and the Determination of Hepatic Insulin Resistance
}

\author{
Po Sing Leung \\ School of Biomedical Sciences, Faculty of Medicine, The Chinese University of Hong Kong, Hong Kong, China; \\ psleung@cuhk.edu.hk; Tel.: +852-3943-6879 \\ Received: 18 April 2019; Accepted: 3 July 2019; Published: 5 July 2019

\begin{abstract}
Vitamin D deficiency or hypovitaminosis D is associated with increased risks of insulin resistance, type 2 diabetes mellitus (T2DM) and its related non-alcoholic fatty liver disease (NAFLD). Meanwhile, inappropriate over-activation of the renin-angiotensin system (RAS) in the liver leads to the hepatic dysfunction and increased risk of T2DM, such as abnormalities in lipid and glucose metabolism. Our previous findings have shown that calcitriol, an active metabolite of vitamin D, reduces hepatic triglyceride accumulation and glucose output in diabetic $\mathrm{db} / \mathrm{db}$ mice and human hepatocellular cell HepG2 cells under insulin-resistant conditions. Notwithstanding the existence of this evidence, the protective action of vitamin $\mathrm{D}$ in the modulation of overexpressed RAS-induced metabolic abnormalities in the liver under insulin resistance remains to be elusive and investigated. Herein, we have reported the potential interaction between vitamin D and RAS; and its beneficial effects on the expression and function of the RAS components in HepG2 cells and primary hepatocytes under insulin-resistance states. Our study findings suggest that hormonal vitamin D (calcitriol) has modulatory action on the inappropriate upregulation of the hepatic RAS under insulin-resistant conditions. If confirmed, vitamin D supplementation might provide a nutraceutical potential as a cost-effective approach for the management of hepatic metabolic dysfunction as observed in T2DM and related NAFLD.
\end{abstract}

Keywords: AT1 receptor calcitriol; HepG2 cells; liver; obesity; pancreas; type 2 diabetes

\section{Main Text}

Hypovitaminosis D is commonly observed in many countries; it is known to be closely associated with increased insulin resistance, impaired insulin secretion, and poorly controlled glucose homeostasis, and thus is correlated with the risk of metabolic diseases, such as type 2 diabetes mellitus (T2DM) and non-alcoholic fatty liver disease (NAFLD). Meanwhile, the liver plays key roles in glucose and lipid metabolism, and its deregulation leads to abnormalities in hepatic glucose and lipid metabolism. In this context, the recent identification of vitamin D receptors (VDR) and of the vitamin-D activating $1 \alpha$-OHase in several non-renal tissues, including the pancreatic islets and liver, explains the diverse physiological roles of vitamin $\mathrm{D}$, in addition to 'classic' effects on calcium and bone homeostasis [1]. The presence of VDR response elements (VDREs) in promoter regions of insulin receptor genes may explain these non-classical effects of vitamin D [2]. Eighty percent of circulating insulin binds to insulin receptors in the liver, which occurs throughout the liver lobules [3]. Hepatic insulin resistance is a consequence of hepatic adiposity and accounts for the majority of the overall insulin resistance, independent of obesity [4]. Reduced hepatic insulin sensitivity in metabolic syndromes, such as type 2 diabetes (T2DM) and non-alcoholic fatty liver disease (NAFLD) [5], may result directly from reduced insulin receptor numbers or indirectly from reduced insulin action via post-insulin receptor 
signalling pathway genes [6]. It may also result from a reduction in Gc globulin (vitamin D binding proteins synthesized by hepatocytes and stored in stellate cells) through reduced megalin or gp330 receptor function [7].

It has been well recognized that hypovitaminosis $D$ is associated with increased risks of NAFLD and hepatic fibrosis with cirrhosis developing in 10\% of such patients [8]. In fact, hypovitaminosis D is associated with increased risks of each component of metabolic syndrome: central obesity, glycemia, blood pressure, adverse lipid profiles, insulin resistance, T2DM, and cardiovascular disease $[9,10]$. The effects of vitamin D on insulin sensitivity have yet to be investigated. In the pancreatic islets, it may be due, in part, to increased intracellular ionised calcium or modulation of the many genes with VDREs in their promoter regions [2]. NAFLD increases hepatic insulin resistance, independent of general obesity in humans [5] while vitamin D inhibits adipogenesis via VDR mediated inhibition of PPAR $\gamma$ activity [11]. Vitamin D is both 25-hydroxylated and activated in the liver by local $1 \alpha$-hydroxylase and there are fully functional VDRs in Kupffer, stellate and endothelial cells as well as in the hepatocytes [12]. In view of this fact, vitamin D could be expected to exert direct effects on hepatic insulin signalling pathway genes and vitamin D supplementation might have a potential for the management of obesity-associated T2DM and NAFLD [1].

The renin-angiotensin system (RAS) is best known as a hormonal system with a physiological role in the maintenance of circulatory and fluid homeostasis, i.e., a classical hormonal system associated with human hypertension and diabetes. Dysregulation of the RAS results in cardiovascular and renal disease as well as metabolic syndromes [13]. Sequential enzymatic cleavage of the circulating renin and angiotensin-converting enzyme (ACE) on the liver angiotensinogen produces angiotensin II, the physiologically active peptide of the system, acting mainly on its respective AT1 and AT2 receptors. In addition, alternative enzymes (e.g., ACE2 and chymase) are able to produce a number of bioactive peptides, such as angiotensin IV, Ang (1-7), and Ang (1-9) [13]. Apart from the classical RAS, local RASs have been identified in various cells and tissues, including the pancreas and liver [14].

Interestingly, it has been previously reported that hypovitaminosis D is associated with increased blood pressure while vitamin D reduces RAS activity through specific suppression of renin secretion [15]. Paradoxically, a fall in systolic blood pressure with vitamin D supplementation in T2DM was associated with falls in angiotensin II but increases in renin in the circulation, suggestive of an alternative mechanism involved [16], probably via a reduction in vascular resistance by vitamin D directly [17]. It has also been further reported that vitamin D is a negative regulator of the RAS and relevant to the regulation of hypertension and cardiovascular disease through downregulation of renin secretion; in addition, RAS activity is increased markedly in VDR-null mice $[18,19]$.

More interestingly, we have recently identified a functionally active islet RAS in the pancreas [20] and the expression and function of this local RAS are also subject to the modulatory action of vitamin D [21]. Indeed, calcitriol, an active form of hormonal vitamin D, can prevent and correct overactive RAS in isolated islets under high-glucose conditions; these effects are in parallel with the well-known action of calcitriol on increasing islet beta-cell glucose-stimulated insulin secretion [20]. Furthermore, we have also demonstrated that mice with diet-induced hypovitaminosis D develop impaired glucose tolerance, increased RAS expression and decreased islet function-related gene transcription [22]. Pharmacological treatment with aliskiren, a renin inhibitor, without vitamin D status correction, has been found to reduce islet RAS overactivity, islet dysfunction and insulin resistance while improving glucose tolerance [22]. These study findings point to RAS inhibition and/or vitamin D supplementation being a potential for ameliorating islet dysfunction and insulin resistance observed in T2DM and NAFLD. In term of the liver, the existence of key components of the RAS while their upregulation and clinical relevance to hepatic dysfunction, such as liver fibrosis, have long been recognized [23,24]. As expected, there is clear evidence for the association of hypovitaminosis D with hypertension and RAS over-activity, whilst vitamin D treatment can lower human blood pressure by suppressing renin formation, reducing RAS activity. On the other hand, RAS blockade appears to be 
protective against T2DM and NAFLD whilst vitamin D supplementation reduces insulin resistance and dysfunction in the liver and pancreas [1].

Interestingly, our more recent study has demonstrated that vitamin $\mathrm{D}$ can protect hepatic function in the context of glucose and lipid metabolism via the mediation of Ca2+/CaMKK $\beta / A M P K$ signaling [25]. Despite these findings, the potential interaction between the RAS and vitamin D in the modulation of hepatic glucose and lipid metabolism has yet to be determined. As expected, our preliminary results showed that major RAS components (e.g., angiotensinogen, AT1/AT2/Mas receptors, and ACE/ACE2) were expressed in the HepG2 cells and isolated hepatocyte cells. Our preliminary data also further showed that high-glucose plus high-insulin culture conditions significantly upregulated the expression of the key RAS components, notably the AT1 receptor in HepG2 cells (unpublished data). In addition, treatment with different concentrations of calcitriol (0.01-10 nM) significantly suppressed the inappropriate activation of the AT1 receptor expression under insulin-resistant state in a dose dependent manner; these inhibitory effects on AT1 receptor were observed from 4 to 6 hours after calcitriol treatment (unpublished data). Interestingly, the beneficial effects of vitamin D on the RAS may be mediated via AMPK-Sirt1 signaling pathway, as demonstrated by the pharmacological use of SIRT1 inhibitor, EX-527 (unpublished data). In corroboration with the HepG2 cells, similar results on the protective effects of calcitriol were also observed in the isolated hepatocytes. These data prompt us to speculate that calcitriol (an active form of vitamin D) has modulatory action on the inappropriate activation of the hepatic RAS under insulin-resistant conditions, and that potential vitamin D supplementation might provide a cost-effective measure for improving hepatic metabolic dysfunction in T2DM and related NAFLD.

Funding: Research Grants Council of Hong Kong, Ref. \# CUHK14107415.

Conflicts of Interest: No conflict of interest reported.

\section{References}

1. Leung, P.S. The potential protective action of vitamin D in hepatic insulin resistance and pancreatic islet dysfunction in type 2 diabetes mellitus. Nutrients 2016, 8, 147. [CrossRef] [PubMed]

2. Wang, T.T.; Tavera-Mendoza, L.E.; Lapierre, D.; Libby, E.; Nagai, Y.; Bourdeau, V.; Konstorum, A.; Lallemant, B.; Zhang, R. Large-scale in silico and microarray-based identification of direct 1,25-dihydroxyvitamin $\mathrm{D}_{3}$ target genes. Mol. Endocrinol. 2005, 19, 2685-2695. [CrossRef] [PubMed]

3. Krones, A.; Kietzmann, T.; Jungermann, K. Perivenous localization of insulin receptor protein in rat liver, and regulation of its expression by glucose and oxygen in hepatocyte cultures. Biochem. J. 2000, 348, 433-438. [CrossRef] [PubMed]

4. Kotronen, A.; Seppata-Lindroos, A.; Bergholm, R.; Yki-Jarvinen, H. Tissue specificity of insulin resistance in humans: Fat in the liver rather than muscle is associated with features of the metabolic syndrome. Diabetologia 2008, 51, 130-138. [CrossRef] [PubMed]

5. Mu, W.; Cheng, X.F.; Liu, Y.; Lu, Q.Z.; Liu, G.L.; Zhang, J.G.; Li, X.Y. Potential nexus of non-alcoholic fatty liver disease and type 2 diabetes mellitus: Insulin resistance between hepatic and peripheral tissues. Mol. Pharmacol. 2019, 9, 1566. [CrossRef] [PubMed]

6. Muoio, D.M.; Newgard, C.B. Mechanisms of disease: Molecular and metabolic mechanisms of insulin resistance and $\beta$-cell failure in type 2 diabetes. Nat. Rev. Mol. Cell Biol. 2008, 9, 193-205. [CrossRef] [PubMed]

7. Gressner, O.A.; Lahme, B.; Gressner, A.M. Gc-globulin (vitamin D binding protein) is synthesized and secreted by hepatocytes and internalized by hepatic stellate cells through $\mathrm{Ca}^{2+}$-dependent interaction with the megalin/gp330 receptor. Clin. Chem. Acta 2008, 390, 28-37. [CrossRef]

8. Van Belle, T.L.; Gysemans, C.; Mathieu, C. Vitamin D and diabetes: The odd couple. Trends Endocrinol. Metab. 2013, 24, 561-568. [CrossRef]

9. Norman, P.E.; Powell, J.T. Vitamin D and cardiovascular disease. Circ. Res. 2014, 114, 379-393. [CrossRef]

10. Mirhosseini, N.; Vatanparast, H.; Mazidi, M.; Kimball, S.M. The effects of improved serum 25-hydroxyvitamin D status on glycemic control in diabetic patients: A meta-analysis. J. Clin. Endocrinol. Metab. 2017, 102, 3097-3110. [CrossRef] 
11. Wood, R.J. Vitamin D and adipogenesis: New molecular insights. Nutr. Rev. 2008, 66, 40-46. [CrossRef] [PubMed]

12. Gascon-Barre, M.; Demers, C.; Mirshahi, A.; Neron, S.; Zaizal, S.; Nanci, A. The normal liver harbors the vitamin D nuclear receptor in non-parenchymal and biliary epithelial cells. Hepatology 2003, 37, 1034-1042. [CrossRef]

13. Chan, Y.C.; Leung, P.S. The renin-angiotensin system and reactive oxygen species: Implications in pancreatitis. Antioxid. Redox Signal. 2011, 15, 2743-2755. [CrossRef] [PubMed]

14. Leung, P.S.; Carlsson, P.O. Pancreatic islet renin-angiotensin system: Its novel roles in islet function and in diabetes mellitus. Pancreas 2005, 30, 293-298. [CrossRef] [PubMed]

15. Li, Y.C.; Qiao, G.; Uskokovic, M.; Xiang, W.; Zheng, W.; Kong, J. Vitamin D: A negative endocrine regulator of the renin-angiotensin system and blood pressure. J. Steroid Biochem. Mol. Biol. 2004, 89, 387-392. [CrossRef] [PubMed]

16. Sugden, J.A.; Davies, J.I.; Witham, M.D.; Morris, A.D.; Struthers, A.D. Vitamin D improves endothelial function in patients with type 2 diabetes mellitus and low vitamin D levels. Diabet. Med. 2008, 25, 320-325. [CrossRef] [PubMed]

17. Norman, P.E.; Powell, J.T. Vitamin D, shedding light on the development of disease in peripheral arteries. Arterioscler. Thromb. Vasc. Biol. 2005, 25, 39-46. [CrossRef]

18. Li, Y.C.; Kong, J.; Wei, M.; Chen, Z.F.; Liu, S.Q.; Cao, L.P. 1,25-dihydroxyvitamin D3 is a negative endocrine regulator of the renin angiotensin system. J. Clin. Investig. 2002, 110, 229-238. [CrossRef]

19. Kong, J.; Li, Y.C. Effect of angiotensin II type 1 receptor antagonist and angiotensin-converting inhibitor on vitamin D receptor null mice. Am. J. Physiol. 2003, 285, R255-R261.

20. Leung, P.S. The physiology of a local renin-angiotensin system in the pancreas. J. Physiol. 2007, 580, 31-37. [CrossRef]

21. Cheng, Q.; Li, Y.C.; Boucher, B.J.; Leung, P.S. A novel role for vitamin D: Modulation of expression and function of the local renin-angiotensin system in mouse pancreatic islets. Diabetologia 2011, 54, 2077-2081. [CrossRef] [PubMed]

22. Cheng, Q.; Boucher, B.J.; Leung, P.S. Modulation of hypovitaminosis D-induced islet dysfunction and insulin resistance through direct suppression of the pancreatic islet renin-angiotensin system in mice. Diabetologia 2013, 56, 553-562. [CrossRef] [PubMed]

23. Paizis, G.; Cooper, M.E.; Schembri, J.M.; Tikellis, C.; Burrell, L.M.; Angus, P.W. Up-regulation of components of the renin-angiotensin system in the bile duct-ligated rat liver. Gastroenterology 2002, 123, 1667-1676. [CrossRef] [PubMed]

24. Yoshiji, H.; Kuriyama, S.; Yoshii, J.; Ikenaka, Y.; Noguchi, R.; Nakatani, T.; Tsujinoue, H.; Fukui, H. Angiotensin-II type 1 receptor interaction is a major regulator for liver fibrosis development in rats. Hepatology 2001, 34, 745-750. [CrossRef] [PubMed]

25. Cheng, S.; So, W.Y.; Zhang, Q.; Cheng, Q.; Boucher, B.J.; Leung, P.S. Calcitriol reduces hepatic accumulation and glucose output through $\mathrm{Ca}+/ \mathrm{CaMKK} \beta / \mathrm{AMPK}$ activation under insulin resistance in type 2 diabetes mellitus. Curr. Mol. Med. 2016, 16, 747-758. [CrossRef] [PubMed]

Sample Availability: Samples of the compounds in this study are available from the authors.

(C) 2019 by the author. Licensee MDPI, Basel, Switzerland. This article is an open access article distributed under the terms and conditions of the Creative Commons Attribution (CC BY) license (http://creativecommons.org/licenses/by/4.0/). 